\title{
Survey on New Generation of Migrant Workers in Need of Vocational Education in South Jiangsu Province on the Background of "Study-aiding \& Make Your Dream Come True"*
}

\author{
Jun Mo \\ Business School \\ Hohai University \\ Nanjing, China, 211100 \\ Wuxi Vocational College of Science and Technology \\ Wuxi, China 214028
}

\author{
Chunmei Mao** \\ School of Public Administration \\ Hohai University \\ Nanjing, China 211100 \\ **Corresponding Author
}

\begin{abstract}
There is a large number of new generation of migrant workers who are in great need of vocational education. According to a questionnaire, this article analyzes the vocational education needed by new generation of migrant workers in South Jiangsu Province as well as relevant barriers in reality. Special surveys are made on the mixed talent training mode on the basis of MOOC, revealing recognition in market and profession related to the MOOC, dissecting the will and ability to pay for vocational education by them. There stand barriers in reality such as information asymmetry, inadequate support in the vocational education market for them, accordingly this article raises relevant suggestions and shows an orientation for the coming researches.
\end{abstract}

Keywords-new generation of migrant workers; vocational education; MOOC; need

\section{INTRODUCTION}

With the coming of Lewis Turning Point, the demographic dividend is gradually disappearing in China, three problems have risen including increased labor costs, aging population and lowered number of total laborers. Therefore a series of strategies have been raised in the country such as population policy, enlarging the efficient supply of human capital and accumulation of intelligence capital. Facing such a background, the Ministry of Education and the All-China Federation of Trade Unions jointly released an Upgrade Program for Degree and Ability

*[Fund Program] Applied Research Quality Theme of Social Science of Jiangsu Province in 2016 "Studies on Vocational Education Training System of New Generation of Migrant Workers on the Background of Supply Side Reform" (16SYC-141); Studies on Philosophy Social Sciences in Colleges of Jiangsu Province, 2015 "Studies on English Teaching Efficiency via Flipped Classroom in Higher Vocational Colleges" (2015SJD377); Teaching Reform Theme of Wuxi Vocational College of Science and Technology in 2015 "Studies on Innovative Construction of Foreign Language Reading Courses on the Perspective of MOOCs' (JG2015109); Social Education Plan Theme of Jiangsu Province in 2016 "Studies on Resource Integration of the Traditional Cultural Literacy Education for Citizens in Wuxi" (JSS-L-2016038). for Migrant Workers-- Study-Aiding \& Make Your Dream Come True Project in Mar 2016, it is planned to fund 1.5 million migrant workers by 2020 , who will receive undergraduate and specialized education, and carry out technical training relative to innovation and startup, which marks that the vocational education of migrant workers has actually entered a stage of academic education.

The researches on migrant workers training in the country can be traced back to the middle of the 1980s when migrant workers rush arose, and mainly contents at that time were mainly involved in production technology, safety knowledge, legal knowledge, health and disease prevention, moral education and so on (Xu Benren, 1994). Seen from these, the migrant workers trainings were focused on training but not academic education. In the meantime, as for the need of migrant workers, most researches were aiming at macroscopic aspects, discussing the demand of economic and social development for migrant workers but little was paid to the development need of migrant workers in the microcosmic aspect (Xie Jianshe, 2007). As far as the special researches on the migrant workers education, there were few researches on the migrant workers themselves, trainees and the parties concerned (Cui Mingxiang, 2009).

After entering the 21 st century, the migrant workers have been renewed, and a new generation migrant workers have become a fresh power among the workers. The migrant workers are highly educated with high expectation in vocation, material and spirit, which has an obvious characteristic of the era, who are in a great need of vocational education. However, generally it is difficult to realize the will, because traditional vocation education mode is unable to train the new generation of migrant workers. Some scholars conduct researches on online higher degree education on migrant workers (Zhang Ziying, 2012, Li Yan, 2011), yet no systematic analysis are made on efficient methods and ways (Lai Xianming, Zeng Dong, 2013). With the development of the MOOC era, the newly rising online 
education mode opens a new way in order to achieve the supply side reform of higher education products and meet the need of vocational education of migrant workers. Therefore, this article makes a questionnaire upon the migrant workers, discussing the need of vocational education and actual barriers for the group so as to provide references for relevant researches.

\section{RESEARCH DESIGN}

\section{A. Problems}

Main problems relative to migrant workers to be researched include:

Basic status quo;

Market potential for vocational education;

Market barriers for vocational education

Where, the second problem contains three sub-problems:

Market recognition of vocational MOOC;

Will and ability to pay for vocational education by migrant workers

\section{B. Research Course}

Based on actual conditions, this survey is conducted on self-made questionnaire. Random questionnaire is made on migrant workers in two regions, South Jiangsu Province. Sep 27-28, 2016, the survey team released and took back 240 questionnaires through sampling migrant workers who attended the job market held by two human resources service centers at Guangrui Road and New Area, with 16 questionnaires invalid removed, 224 of which were valid (called urban samples). Afterwards, Oct 14-16, 21-23, 2016, the survey team released and took back 200 questionnaires through sampling migrant workers who were employed by two employers at Liantang Town and Shajiabang, Changshu City respectively, with 19 questionnaires invalid removed, 181 of which were valid (called town samples). Statistical analysis is conducted on the 405 questionnaires.

\section{RESEARCH RESULT AND DISCUSSION}

\section{A. Considerable Migrant Workers for Vocational Education}

At present, the new generation of migrant workers refers to those who were born after the 1980 s, aged 16 or more, registered as farmers but engaged in non-farming jobs in other cities. According to the data stated in the 2015 Monitoring and Survey Report on Migrant Workers made by National Bureau of Statistics, in 2015, there were 277.47 million migrant workers throughout the country, those aged 40 or less occupied $55.2 \%$, totaling 153.16 million. The survey shows that the proportion between male and female migrant workers in South Jiangsu Province is 125: 100, which is in a lower gap. Seen from the age structure, those aged $20-30$ occupy $59.51 \%$, who are suitable for vocational education. Of whom, those who receive high school/college education occupy $54.57 \%$.

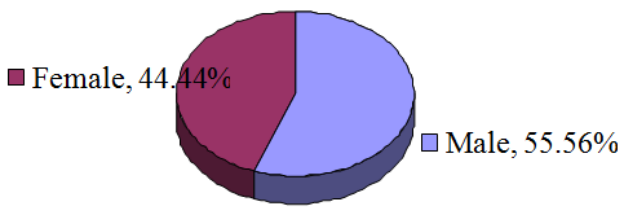

Fig. 1. Sex Statistics.

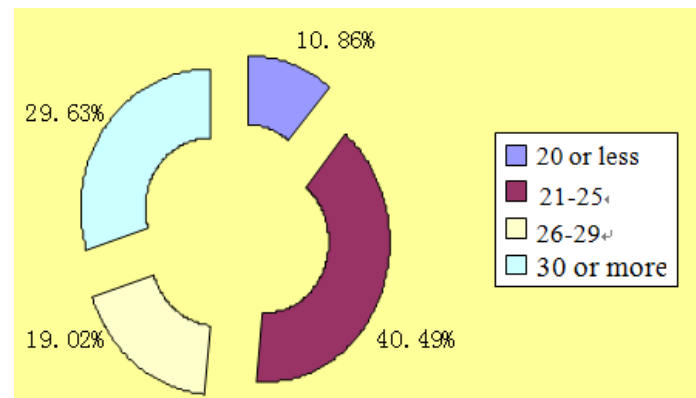

Fig. 2. Age Statistics.

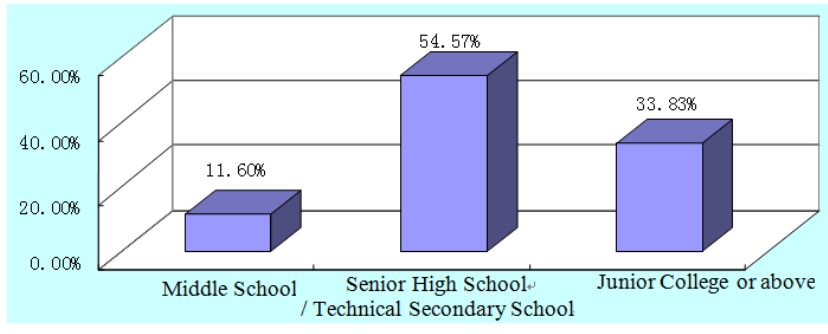

Fig. 3. Education Background Statistics.

\section{B. Unlimited Market Potentials for Vocational Education of Migrant Workers}

Vocational MOOCs refer to online courses which are based on project design or problem solution and open for experiment (practice) of interdisciplinary innovation (Chen Yukun, 2015). Compared to knowledge point-based MOOCs, the vocational MOOCs are technical and skillful online course system. This article conducts special researches on the mixed talent training mode on the basis of vocational MOOC, considering the educational background and acceptance, straightaway online courses are adopted in the questionnaires to replace the special vocational MOOCs.

\section{1) Market recognition of vocational MOOCs}

Seen from the market recognition of vocational MOOCs, $32.59 \%$ of migrant workers think it not strange, which to some degree proves that the thoughts of the migrant workers are open and active (Zeng Yuelin, 2013), yet the urban-rural difference is distinct (56.7\% in urban samples, $2.76 \%$ in town samples). Based on the above, within the vocational training and degree education, the average recognition of vocational MOOCs is about $40 \%$, yet there is a $20 \%-25 \%$ deviation between the urban-rural samples and average value, therefore, it can be seen that the mixed talent training mode on the basis of vocational MOOCs can be accepted at least by about half of the trainees, however, the market at towns still needs to be promoted. 


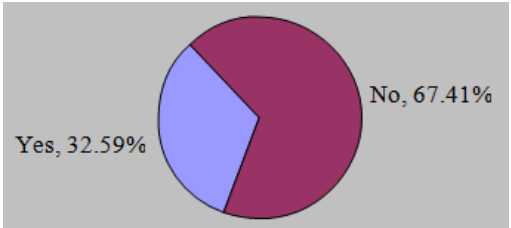

Fig. 4. Have you ever watched online vocational training courses?

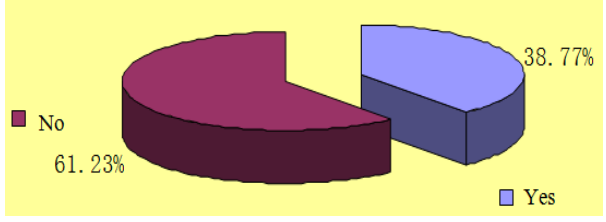

Fig. 5. Do you think it okay to accept the online vocational training?

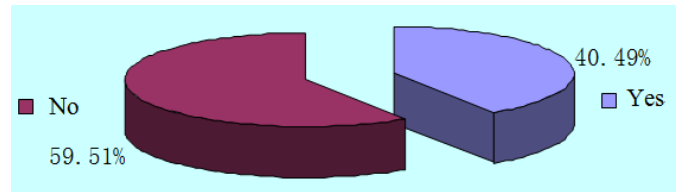

Fig. 6. Would you like to accept the online course for degree upgrade?

2) Special recognition of vocational MOOCs: The wills of migrant workers in training are diverse, this research aims at English, computer and so on which are popular in the society. The results show the recognition of computer occupies about $40 \%$, English occupies about $30 \%$ market share, seen from these, facing current situations, computer and English, two traditional courses in colleges, are still full of energy, attracting eyeballs of $70 \%$ of migrant workers. Limited by the work and types, accounting and secretarial attract 15\% of trainees, and the rest $15 \%$ is occupied by other specialties with higher technicality.

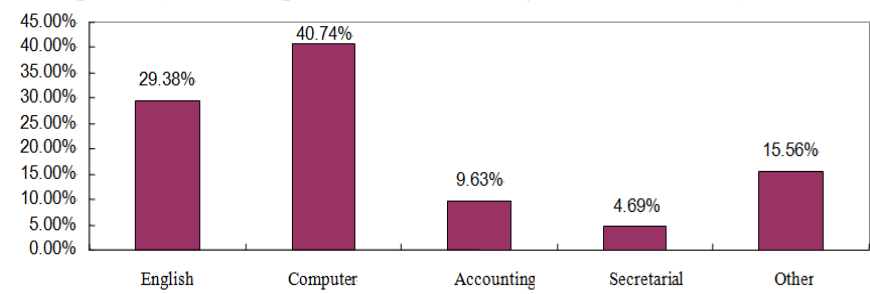

Fig. 7. Which online training courses you will accept?

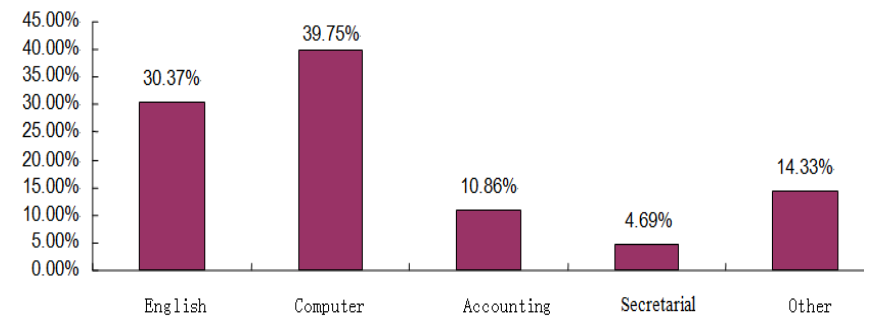

Fig. 8. What's the online degree training course you will accept?
3) Will and ability to pay for vocational education by migrant workers.

A focus problem found through the survey is the relations between income level, wills and abilities to pay for vocational education of migrant workers. Sampling results show, at present, the overall quality of the migrant workers is higher, about $70 \%$ of which have monthly income totaling 2500 Yuan or more $(69.64 \%$ in urban samples, $55.22 \%$ in town samples), compared to the past, the freely distributable income is increased. Take the "study-aid and make your dream come three project" in Jiangsu Province as an example, the migrant workers who participate in degree education may get subsidy of 500 Yuan each as well as tuition preference totaling 500-1500 Yuan donated by colleges concerned and "work union encouragement bonus" totaling 500-2000 Yuan donated by federation of trade union. Considering that about $60 \%$ recipients agree to pay 1500 Yuan (tuition fee) for vocational education through vocational MOOCs, their actual payment will be kept at about 5500 Yuan averagely, basically similar to about 6000 Yuan (tuition fee) in state-run colleges.

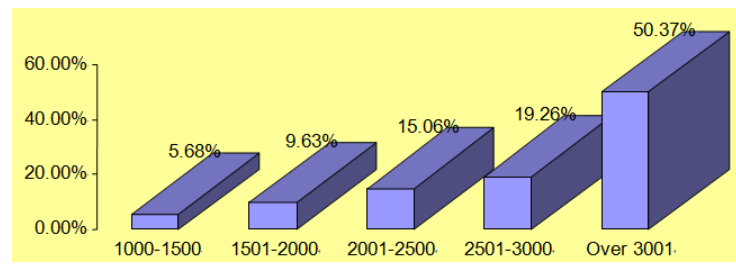

Fig. 9. Monthly Income Statistics.

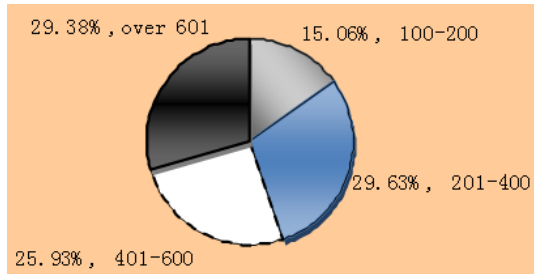

Fig. 10. How much will you pay for an online vocational training course?

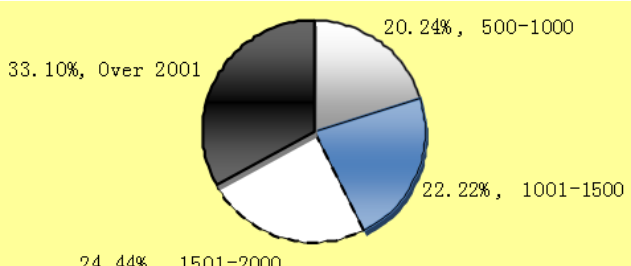

$24.44 \%, 1501-2000$

Fig. 11. How much will you pay for the online degree education within half a year?

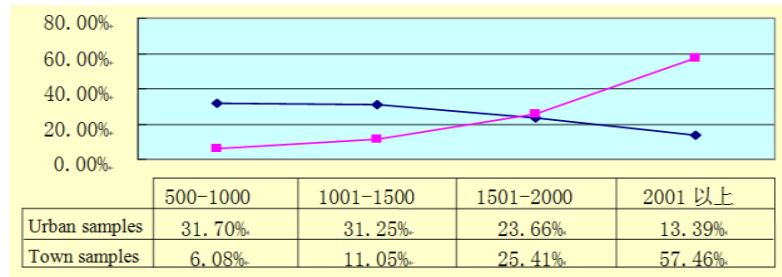

Fig. 12. How much will you pay for the online degree education within half a year? (Urban-rural comparison) 
As for the will for payment, the difference between urban and town samples forms a remarkable inverse relation. Generally though the income level of town samples is a little lower than that of urban samples, yet the will for payment of the town samples is obviously higher than that of the urban samples, over half of town samples agree to pay more for degree education, which reflects that the migrant workers specially agree to get rid of the trouble in work through investment in education and get improved; on the other hand, the potential of vocational education market in towns is huge.

\section{Barriers for the Vocational Education Market of Migrant Workers}

An indirect intension of the survey is to promote the "study aiding and make your dream come true" project, and the survey found that from the release of the project by the Ministry of Education and All-China Federation of Trade Union in Mar 2016, about $15 \%$ of migrant workers in Wuxi and Changshu have got the information via all kinds of channels within half a year (urban samples: $25.9 \%$, town samples: $1.66 \%$ )

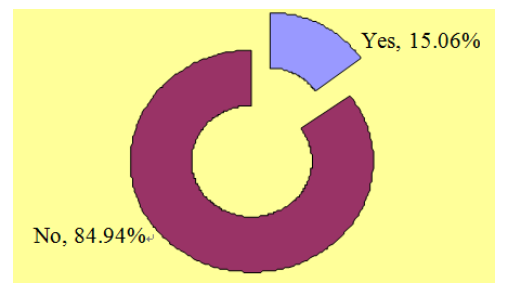

Fig. 13. Do you know the "study aiding and make your dream come true" project"?

Though the proportion still has a big room for increase, it has to depend on the publicity from cities to villages by social fields under the support of governments. Yet seen from the questionnaire results, it reflects that the migrant workers are generally showing a favorable attitude to the project. When asked "what's your opinion about the "study-aiding and make your dream come true" project launched by the Ministry of Education? About 90 persons/times express "like" explicitly, some think, the policy turns out that state policies have been improved and the state becomes powerful; it may help improve the people's quality and support the low-income groups. Some posts comments "please enlarge the scope", some say they will encourage more to attend.

Yet the survey also found that there are serious barriers in reality. Due to the frequent flow of migrant workers and low-continuity of vocational development, you will always find the characteristics of labor capital "high will for training", "low proportion to participate" (He Zhen, 2013), and the view "it is hard to do" of some respondents also proves this problem. On the fees, some respondents say that "as long as they are not cheated, they will do it", and some hope to "less pay". What is important is some respondents still have doubts about it, hoping "really carry it out on migrant workers", and some even ask: "Is there any restriction? It is only applicable for those who are closely related to government officials? These are inevitable doubt and challenges to the social credibility and execution of state policies.

In the meantime, the fees for vocational education are tough barriers in reality. The survey shows, most of the migrant workers earn income day by day, and their monthly pay is still considerable, and any work suspension will cause serious economic loss. By contrast, the exemption of hundreds of tuition fees and even thousand of subsidies are difficult to attract the migrant workers to stop their work to receive the degree education bringing no obvious benefits.

\section{CONCLUSION}

Based on the questionnaire surveys on migrant workers in South Jiangsu Province, this article masters basic conditions and vocational education needs of the group as well as the potential and barriers on the vocational education market of migrant workers. This article reveals the migrant workers' recognition in market and specialty relative to the vocational MOOCs, it provides references and basis for the high vocational education supply reform in the Internet plus era with the MOOC as a carrier. In the meantime, the research finds that some impersonal factors that block the migrant workers from vocational education mainly include training information asymmetry, failure of preferential policies to reach the targeted group in time, validly and as expected, low strength of funding policies and so on. Accordingly the following measures should be taken: I. Promote the policy publicity; II. Take active measures to remove the troubles of migrant workers; III. Develop more channels to increase the support in costs.

Theories and empirical studies relative to human capital show, the investment in education has a higher rate of return in productivity (Psacharopoulos, 1984 ; Leslie \& Brinkman, 1988), in the opinion of the Public Health of Nations, the development of migrant worker's education will be the spring of public wealth in the future (Li Minghua, 2011). 2016 was the first year for the country to launch "study-aiding and make your dream come true" the project, facing new policies, a large number of respondents, a series of barriers as well as characteristics of long degree education period, in the coming five years, the research of the theme group may be focused on the two fields: I. Study on relations between governmental financial investment strength and participation of migrant workers; II. Study on different needs of vocational training of migrant workers who go out and return due to the differences in regions.

\section{REFERENCES}

[1] Xu Beiren, New Topics of Migrant Worker Rush for Adult Education in Rural Areas [J]. China Adult Education, 1994,(12): 14-15.

[2] Xie Jianshe, Li Mingze, General Studies on Migrant Workers Education [J].Study and Practice, 2007, (4): 121-130. 
[3] Cui Mingxiang, Research on Migrant Workers Training Since Reform [J]. Journal of Hebei Normal University/Educational Science Edition, 2009, 11(3): 93-96.

[4] Zhang Ziying, Roles of Online Remote Education on Training of Migrant Workers Training [J]. Continue Education Research, 2012, (5): 25 .

[5] Li Yan, Studies on Modern Remote Education Mode for Migrant Workers [J]. Education and Vocation, 2011(29): 160-161.

[6] Lai Xianming, Zeng Dong, General Studies on Higher Education of New Generation of Migrant Workers [J]. Journal of Guangzhou Open University, 2013, (2): 21-25.

[7] Zeng Yuelin, Li Jian, Luo Shiwen, Studies on Ways for Higher Vocational Colleges to Participate in the Training of New Generation of Migrant Workers-based on Jiangxi College of Applied Technology [J]. Adult Education, 2013, (5): 54-56.

[8] He Zhen, Li Chen, Break the Dilemma of New Generation of Migrant Workers with High Will for Training but Low Participation, base on human capital characteristics and enterprise training [J].Educational Research, 2013, (2): 105-110.

[9] Psacharopoulos, George. The Contribution of Education to Economic Growth: International Comparisons. In John W. Kendrick (Ed.), International Comparisons of Productivity and Causes of the Slowdown [M] . Cambridge: Ballinger Pub. Co., 1984.

[10] Leslie, L. L and Brinkman, Paul. T. The Economic Value of Higher Education $[\mathrm{M}]$.New York: American Council on Education and Macmillan Publishing Co.

[11] Li Minghua, Studies on Demand Supply and Certification System Relative to Migrant Workers [M].Beijing: China Yanshi Press, 2011: 92-112. 